\title{
Mars-van Krevelen-like Mechanism of CO Hydrogenation on an Iron Carbide Surface
}

\author{
Jose M. Gracia $\cdot$ Frans F. Prinsloo • \\ J. W. Niemantsverdriet
}

Received: 21 August 2009/Accepted: 30 September 2009/Published online: 15 October 2009

(C) The Author(s) 2009. This article is published with open access at Springerlink.com

\begin{abstract}
Computational chemistry is used to explore a mechanism for $\mathrm{CO}$ hydrogenation to methane on iron carbides. As $\mathrm{CO}$ dissociation is endothermic on carbon terminated $\mathrm{Fe}_{5} \mathrm{C}_{2}$ (100) cuts, we explore a path starting with the hydrogenation of the surface, which liberates iron 4-fold sites for adsorption and dissociation of CO. The reaction cycle to methane resembles the Mars-van Krevelen mechanism for oxidation reactions.
\end{abstract}

Keywords CO hydrogenation .

Fischer-Tropsch synthesis - Iron carbide $\mathrm{Fe}_{5} \mathrm{C}_{2}$.

DFT · Mars-van Krevelen mechanism

\section{Introduction}

The Fischer-Tropsch Synthesis (FTS) is the catalytic conversion of synthesis gas $\left(\mathrm{CO}+\mathrm{H}_{2}\right)$ into hydrocarbons over catalysts based on iron, cobalt, nickel or ruthenium $[1,2]$ and is of great importance for the conversion of natural gas, coal or biomass via synthesis gas into liquid fuels and chemicals. While metallic cobalt is the catalyst of choice for modern Gas-to-Liquids plants, conversion of coal and biomass to liquids relies largely on iron catalysts. Nickel is mainly a methanation catalyst, and ruthenium is

J. M. Gracia $(\bowtie)$ J. W. Niemantsverdriet

Schuit Institute of Catalysis, Eindhoven University of

Technology, P.O. Box 513, 5600 MB Eindhoven,

The Netherlands

e-mail: budricop@gmail.com

F. F. Prinsloo

Sasol Technology R\&D (Pty) Limited, P.O. Box 1, Sasolburg

1947, South Africa not commercially applied. A fully reduced iron metal catalyst shows no activity for FTS, but becomes active along with its conversion into carbides [3-5]. Ab initio studies providing new insights into the surface chemistry of iron carbide surfaces as FTS catalysts have been published by several authors [6-8]. Nevertheless, a mechanistic description in terms of elementary steps along with potential energy changes has not yet been presented for the $\mathrm{CO}$ hydrogenation over iron carbides and forms the subject of this communication.

The high selectivity of metals such as copper or palladium to methanol from synthesis gas rather than hydrocarbons reflects their inability to dissociate carbon monoxide. Dissociation of CO, be it assisted by hydrogen or not, is generally seen as the first step in the reaction mechanism, after which $\mathrm{CH}_{x}$ species may further react to hydrocarbons [9]. The stability of transition metal carbides increases towards the left across the periodic table, e.g., from $\mathrm{Ni}$ to Fe. Optimum metal-carbon bond strength is a key parameter in the selectivity of the $\mathrm{CO}$ hydrogenation. Weak and strong bonding of carbon atoms leads to mostly methane formation, while intermediate bonding leads to longer hydrocarbons [10-12]. In case of nickel, FTS selectivity toward $\mathrm{C}_{2+}$ hydrocarbons has been suggested to be related to the extent of carbide formation [13, 14]. With cobalt, a correlation between the presence of $\mathrm{CO}_{2} \mathrm{C}$ and a high selectivity to methane has been reported [15]. On iron-based catalysts, studies report a fast and reversible exchange of $\mathrm{Fe}_{3} \mathrm{O}_{4}$ into $\mathrm{Fe}_{x} \mathrm{C}$ carbides and vice versa depending upon reaction environment, as a consequence of elementary FTS steps $[16,17]$, whereas the activity can be correlated with the iron carbide surface area [18]. The facile transformation of the catalytic phases makes it likely that carbon atoms in the surface become incorporated into reaction products [19], in a way that is similar as in 
oxidation catalysis, where the Mars-van Krevelen mechanism is commonly invoked [20].

The FTS product spectrum of iron catalysts is a mix of hydrocarbons and oxygenates, providing support that not all $\mathrm{CO}$ on the surface of the active iron catalyst dissociates, which evidences that the carburization/oxidation of the iron surface diminishes its propensity to dissociate carbon monoxide to some extent [21]. CO dissociation on metallic surfaces becomes more likely as the heat of adsorption for molecular CO increases [22-24], associated to the energies of formation of carbides and oxides [25, 26].

The purpose of this paper is to explore how the CO hydrogenation may occur on the carbon-saturated surface of iron carbide. We do this in a molecular modelling approach with density functional theory (DFT) starting from the carbon-terminated $\mathrm{Fe}_{5} \mathrm{C}_{2}$ (100) [7]. We acknowledge that this surface is not necessarily the prevalent one under Fischer-Tropsch conditions, and that other $\mathrm{Fe}_{5} \mathrm{C}_{2}$ surface structures, as considered by Steynberg et al. [7] and by Sorescu [8] should also receive attention. However, the carbon-terminated $\mathrm{Fe}_{5} \mathrm{C}_{2}$ (100) surface has the highest carbon content and is therefore anticipated to exhibit the lowest reactivity towards $\mathrm{CO}$. In this communication we report adsorption energies of all relevant intermediates towards methane, we provide the thermodynamic parameters for the elementary surface reactions and we propose an overall path for the $\mathrm{CO}$ hydrogenation on this carbon-rich surface of $\mathrm{Fe}_{5} \mathrm{C}_{2}$.

\section{Theoretical Details}

We performed spin-polarized DFT calculations using VASP, the Vienna Ab initio Simulation Package, a program which combines ab initio total energy with planewave basis sets [27-30]. The electron-ion interactions for $\mathrm{H}, \mathrm{C}, \mathrm{O}$, and $\mathrm{Fe}$ atoms are described by the projector augmented wave (PAW) method developed by Blöchl [31]. The exchange correlation energy of the electrons is treated within the revised form of the Perdew, Burke and Ernzerhof GGA, generalized-gradient approximation, functional proposed by Hammer et al. [32], RPBE. We use a cut-off energy of $400 \mathrm{eV}$ for the expansion of the wave function into plane waves. The Monkhorst-Pack scheme is chosen for the integration in the reciprocal space [33]. Geometry relaxations stopped when all the forces of the atoms free to relax were smaller than $0.01 \mathrm{eV} / \AA$. Computational parameters were considered to be inside the expected error window for the RPBE functional of about $0.25 \mathrm{eV}$ for adsorption energies.

A $\mathrm{p}(1 \times 1)$ structure of the $\mathrm{Fe}_{5} \mathrm{C}_{2}(100)-0.05$ unit cell cleavage was used as surface cell in our calculations, including a gap of $10 \AA$ between slabs. Half of the atoms
(14) in the upper layers are free to relax, while the lower half were kept at the optimized position of the bulk $\mathrm{Fe}_{5} \mathrm{C}_{2}$ phase.

\section{Results and Discussion}

In order to study $\mathrm{CO}$ hydrogenation on iron carbides, we have chosen the (100) surface of the $\mathrm{Fe}_{5} \mathrm{C}_{2}$ Hagg carbide, with the unit cell shifted slightly downward to obtain the carbon-terminated surface, following the work of Steynberg et al. [7]. This surface, shown in Fig. 1, has a minimum free energy and exhibits the highest possible carbon content.

The adsorption features of this $\mathrm{Fe}_{5} \mathrm{C}_{2}$ (100) surface are very much determined by the fact that all high coordination $\mathrm{Fe}$-sites are occupied by carbon atoms. The maximum adsorption energy for $\mathrm{CO}$ appears for the on top positions, $E_{\mathrm{ADS}}=1.30 \mathrm{eV}$; adsorption on a carbidic carbon is clearly less favourable with $E_{\mathrm{ADS}}=0.51 \mathrm{eV}$. If one of the $\mathrm{C}_{\mathrm{CARBIDE}}$ atoms is removed from the surface, the $\mathrm{CO}$ adsorption energy on the 4-fold iron site increases to $1.52 \mathrm{eV}$. Although CO thus adsorbs readily on iron carbides, it is the dissociation step that is difficult to envisage on a surface saturated by carbon atoms, which inevitably will cause repulsion with the eventual dissociation products of $\mathrm{CO}$. We find a 'non-productive' dissociation of on-top $\mathrm{CO}$ (Fig. 2) which leads to a $\mathrm{C}_{2}$ fragment and another $\mathrm{CO}$ formed from an initially lattice-carbidic carbon, but the process is endothermic by $1.57 \mathrm{eV}$.

As a fully carburized surface cannot explicitly activate the $\mathrm{C}-\mathrm{O}$ bond, we have explored alternative ways, in which surface carbidic atoms are hydrogenated first. Figure 3 shows the potential energy changes, following the order of steps included in Table 1 , for the reaction $\mathrm{CO}+3 \mathrm{H}_{2} \rightarrow$ $\mathrm{CH}_{4}+\mathrm{H}_{2} \mathrm{O}$. Note that the structures have been simplified and do not exactly represent the geometry of the $\mathrm{Fe}_{5} \mathrm{C}_{2}$ (100) carbide surface. All calculations, however, have been done using the correct structures.

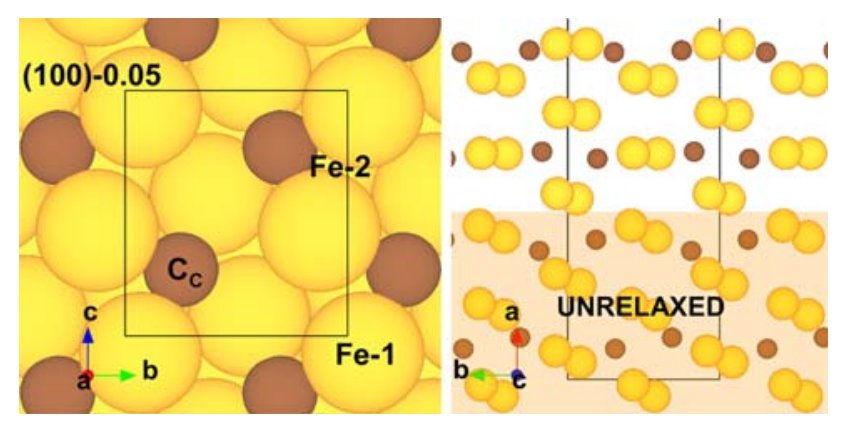

Fig. 1 Top and side views of the stoichiometric $\mathrm{Fe}_{5} \mathrm{C}_{2}$ (100)-0.05 slab model, $\mathrm{p}(1 \times 1)$ unit cell with some adsorption sites: $\mathrm{Fe}-1=\mathrm{Fe}$ on-top, $\mathrm{Fe}-2=\mathrm{Fe}$-bridge and $\mathrm{C}_{\mathrm{C}}=\mathrm{C}_{\mathrm{CARBIDE}}$ in an 4-fold position $(\mathrm{Fe}-4)$ 


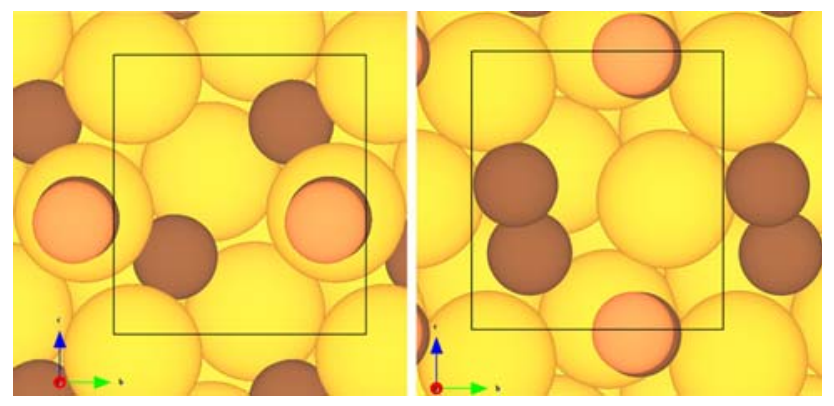

Fig. 2 Most stable conformation for $\mathrm{CO}$ adsorption on $\mathrm{Fe}_{5} \mathrm{C}_{2}$ (100)0.05 (left) and after dissociation, creating $\mathrm{C}_{2}$ and $\mathrm{C}_{\mathrm{CARBIDE}}-\mathrm{O}$ species (right)
As Fig. 3 and Table 1 show, sequential hydrogenation steps of the lattice carbidic carbon show favourable enthalpy changes and, in fact, a significant exothermicity is found for the formation of a methyl group. While $\mathrm{C}_{\mathrm{CARBIDE}^{-}} \mathrm{H}$ (S1) units retain the $\mathrm{Fe}$-4-fold coordination, $\mathrm{CH}_{2}(\mathrm{~S} 2)$ and $\mathrm{CH}_{3}$ (S3) reside in bridge positions between two iron atoms. In this way, a 4-fold position becomes free and is thus available for the adsorption of $\mathrm{CO}$. We observe that in the presence of coadsorbed $\mathrm{CO}$ on Fe-4-fold sites, the methyl group prefers the $\mathrm{C}_{\mathrm{CARBIDE}}-\mathrm{CH}_{3}$ or ethylidyne conformation over adsorption on the Fe-bridge site (Fig. 4). Ethylidyne species are common in the adsorption of ethylene on a variety
Fig. 3 Calculated energy diagram for the proposed $\mathrm{MvK}$ mechanism on $\mathrm{Fe}_{5} \mathrm{C}_{2}$ (100)-0.05 surface for the reaction: $\mathrm{CO}+3 \mathrm{H}_{2} \rightarrow \mathrm{CH}_{4}+\mathrm{H}_{2} \mathrm{O}$

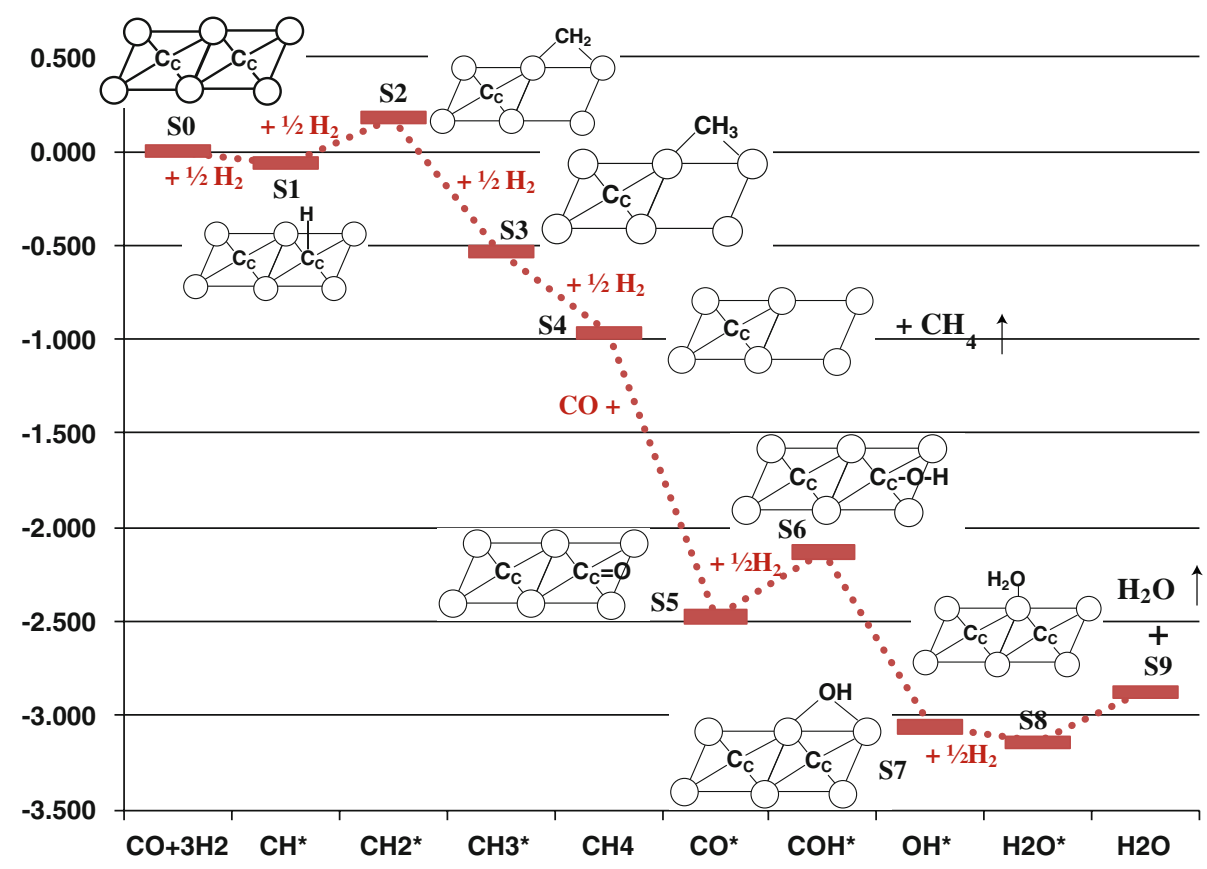

Table 1 Enthalpy changes in $\mathrm{eV}$ during studied elementary steps in methane formation on model $\mathrm{Fe}_{5} \mathrm{C}_{2}(100)-0.05$

\begin{tabular}{llrr}
\hline Step & Reaction & Enthalpy (eV) & Cumulative (eV) \\
\hline $\mathrm{S} 0 \rightarrow \mathrm{S} 1$ & $1 / 2 \mathrm{H}_{2}+\mathrm{C}(\mathrm{Fe}-4) \rightarrow \mathrm{CH}(\mathrm{Fe}-4)$ & -0.07 & -0.07 \\
$\mathrm{~S} 1 \rightarrow \mathrm{S} 2$ & $1 / 2 \mathrm{H}_{2}+\mathrm{CH}(\mathrm{Fe}-4)+\mathrm{Fe}-2 \rightarrow \mathrm{CH}_{2}(\mathrm{Fe}-2)+\mathrm{Fe}-4$ & 0.24 & 0.18 \\
$\mathrm{~S} 2 \rightarrow \mathrm{S} 3$ & $1 / 2 \mathrm{H}_{2}+\mathrm{CH}_{2}(\mathrm{Fe}-2) \rightarrow \mathrm{CH}_{3}(\mathrm{Fe}-2)$ & -0.71 & -0.53 \\
$\mathrm{~S} 3 \rightarrow \mathrm{S} 4$ & $1 / 2 \mathrm{H}_{2}+\mathrm{CH}_{3}(\mathrm{Fe}-2) \rightarrow \mathrm{CH}_{4}+\mathrm{Fe}-2$ & -0.43 & -0.96 \\
$\mathrm{~S} 4 \rightarrow \mathrm{S} 5$ & $\mathrm{CO}+\mathrm{Fe}-4 \rightarrow \mathrm{CO}(\mathrm{Fe}-4)$ & -1.51 & -2.48 \\
$\mathrm{~S} 5 \rightarrow \mathrm{S} 6$ & $1 / 2 \mathrm{H}_{2}+\mathrm{CO}(\mathrm{Fe}-4) \rightarrow \mathrm{COH}(\mathrm{Fe}-4)$ & 0.35 & -2.13 \\
$\mathrm{~S} 6 \rightarrow \mathrm{S} 7$ & $\mathrm{COH}(\mathrm{Fe}-4)+\mathrm{Fe}-2 \rightarrow \mathrm{OH}(\mathrm{Fe}-2)$ & -0.93 & -3.06 \\
$\mathrm{~S} 7 \rightarrow \mathrm{S} 8$ & $1 / 2 \mathrm{H}_{2}+\mathrm{OH}(\mathrm{Fe}-2)+\mathrm{Fe}-1 \rightarrow \mathrm{H}_{2} \mathrm{O}(\mathrm{Fe}-1)+\mathrm{Fe}-2$ & -0.08 & -3.14 \\
$\mathrm{~S} 8 \rightarrow \mathrm{S} 9$ & $\mathrm{H}_{2} \mathrm{O}(\mathrm{Fe}-1) \rightarrow \mathrm{H} \mathrm{O}+\mathrm{Fe}-1$ & 0.26 & -2.88 \\
\hline & $\mathrm{Overall} \mathrm{reaction}$ & & -2.88 \\
\hline $\mathrm{S} 0 \rightarrow \mathrm{S} 9$ & $3 \mathrm{H}_{2}+\mathrm{CO} \rightarrow \mathrm{CH}_{4}+\mathrm{H}_{2} \mathrm{O}$ & \\
\hline
\end{tabular}




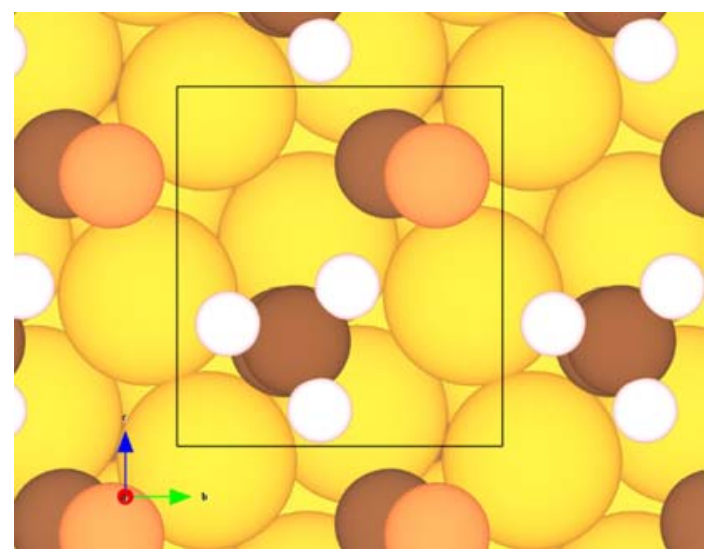

Fig. 4 Most stable configuration for the coadsorption of $\mathrm{CO}$ and 3 hydrogen atoms on $\mathrm{Fe}_{5} \mathrm{C}_{2}(100)-0.05$

of surfaces [34]. Interestingly, initiation of FTS by $\mathrm{C}_{2}$ surface species has been noted by a number of workers [35].

Hydrogenation of the lattice carbidic carbon yields a surface with the methyl species on the bridge position and an open fourfold site (S0-S3), where CO can adsorb (S5). As a result of this the methyl group shifts to the adjacent carbide atom. Hydrogenation of the methyl group yields methane which desorbs instantaneously (S4). Because oxygen atoms prefer to adsorb on top of carbidic atoms if no $\mathrm{Fe}$-4-fold hollow is available, direct dissociation of $\mathrm{CO}(\mathrm{Fe}-4)$ would be thermo-neutral and unproductive. According to Sorescu, the activation barrier for $\mathrm{CO}$ dissociation in Fe binding sites would be at least $1.5 \mathrm{eV}$ [8]. Following a mechanism proposed by Andersson et al. for nickel surfaces [36], reaction of the adsorbed $\mathrm{CO}$ with hydrogen prior to dissociation offers an alternative route for activation of the $\mathrm{CO}$ bond. Although the formation of $\mathrm{COH}$ is endothermic by $0.35 \mathrm{eV}$, the dissociation of $\mathrm{COH}$ is exothermic by $0.93 \mathrm{eV}$, making the overall dissociation reaction from $\mathrm{CO}+\mathrm{H}$ to $\mathrm{C}_{\text {carbide }}+\mathrm{OH}$ almost $0.6 \mathrm{eV}$ exothermic (S6). The $\mathrm{C}-\mathrm{OH}$ bond rupture leaves the surface in almost restored condition with the carbon atom in the 4-fold hollow, and the $\mathrm{OH}$ group on a Fe-bridge position (S7). The exothermic reaction of the $\mathrm{OH}$ with $\mathrm{H}$ towards $\mathrm{H}_{2} \mathrm{O}$ completes the catalytic cycle ( $\mathrm{S} 8-\mathrm{S} 0$ ).

The catalytic cycle for $\mathrm{CO}$ hydrogenation on carbon saturated iron surfaces is sketched in Fig. 5. In summary, as $\mathrm{CO}$ dissociation is strongly endothermic on the carbon saturated $\mathrm{Fe}_{5} \mathrm{C}_{2}$ (100) surface, we explored a mechanism starting with the exothermic hydrogenation of a surface carbon to $\mathrm{CH}_{3}$. This liberates a site of 4-fold coordination between iron atoms, which becomes available for $\mathrm{CO}$ adsorption and most likely hydrogen-assisted dissociation in a $\mathrm{C}_{\mathrm{CARBIDE}}$ atom and an $\mathrm{OH}$ group. The latter process restores the carbide surface, while the $\mathrm{OH}$ group forms water, and $\mathrm{CH}_{3}$ forms methane. The overall reaction cycle

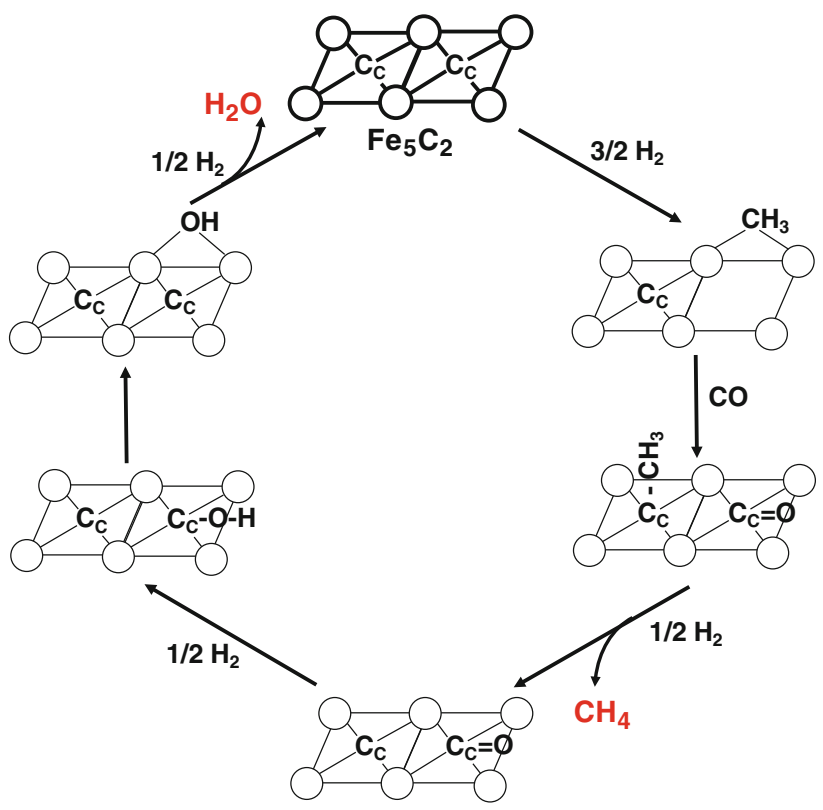

Fig. 5 Schematic representation of the MvK mechanism for FTS towards methane on iron carbide catalysts. Note the full sequence of elementary steps is not necessarily included

resembles the Mars-van Krevelen mechanism for catalytic oxidation reactions [20]. We propose this mechanism based on the experimental observation that metallic iron catalysts convert to iron carbides under Fischer-Tropsch reaction conditions, during which it develops activity for the formation of hydrocarbons. This process can be seen as a self assembly of the catalyst towards a state which can accommodate $\mathrm{CO}$ activation together with hydrocarbon formation in an energetically more favourable way than is possible by the original catalyst.

Acknowledgements We thank the Stichting Nationale Computerfaciliteiten (NCF) for providing supercomputer time at SARA in Amsterdam.

Open Access This article is distributed under the terms of the Creative Commons Attribution Noncommercial License which permits any noncommercial use, distribution, and reproduction in any medium, provided the original author(s) and source are credited.

\section{References}

1. Fischer F, Tropsch H (1926) Chem Ber 59:830

2. Van Der Laan GP, Beenackers AACM (1999) Catal Rev 41:255

3. Raupp GB, Delgass WN (1979) J Catal 58:348

4. Niemantsverdriet JW, van der Kraan AM, Van Dijk WL, Van der Baan HS (1980) J Phys Chem 84:3363

5. Niemantsverdriet JW, van der Kraan AM (1981) J Catal 72:385

6. Cao D-B, Zhang F-Q, Li Y-W, Wang J, Jiao H (2005) J Phys Chem B 109:10922

7. Steynberg PJ, van den Berg JA, van Rensburg WJ (2008) J Phys Condens Matter 20:064238 
8. Sorescu DC (2009) J Phys Chem C 113:9256

9. Rofer-dePoorter CK (1981) Chem Rev 81:447

10. Koerts T, van Santen RA (1992) J Mol Catal 74:185

11. Ducreux O, Rebours B, Lynch J, Roy-Auberger M, Bazin D (2009) Oil Gas Sci Technol Rev IFP 64:49

12. Joyner RW, Darling GR, Pendry JB (1988) Surf Sci 205:513

13. Barbier A, Pereira EB, Martin GA (1997) Catal Lett 45:221

14. Triantafyllopoulos NC, Neophytides SG (2003) J Catal 217:324

15. Xiong J, Ding Y, Wang T, Yan L, Chen W, Zhu H, Lu Y (2005) Catal Lett 102:265

16. Li S, Ding W, Meitzner GD, Iglesia E (2002) J Phys Chem B 106:85

17. Pirola C, Bianchi CL, Di Michele A, Vitali S, Ragaini V (2009) Catal Comm 10:823

18. Perez-Alonso FJ, Herranz T, Rojas S, Ojeda M, Lopez Granados M, Terreros P, Fierro JLG, Gracia M, Gancedo JR (2007) Green Chem 9:663

19. Matsumoto H, Bennett CO (1978) J Catal 53:331

20. Mars P, van Krevelen DW (1954) Chem Eng Sci Spec Suppl 3:41

21. Bian GZ, Oonuki A, Koizumi N, Nomoto H, Yamada M (2002) J Mol Catal A Chem 186:203

22. Joyner RW (1979) Surf Sci 80:215
23. Joyner RW, Roberts MW (1974) Chem Phys Lett 29:447

24. Scheijen FJE, Curulla-Ferre D, Niemantsverdriet JW (2009) J Phys Chem C 113:11041

25. Benziger JB (1980) Appl Surf Sci 6:105

26. Ponec V, van Barneveld WA (1979) Ind Eng Chem, Prod Res Dev 18:268

27. Kresse G, Hafner J (1993) J Phys Rev B 47:558

28. Kresse G, Hafner J (1994) J Phys Rev B 49:14251

29. Kresse G, Furthmuller J (1996) J Comput Mater Sci 6:15

30. Kresse G, Furthmuller J (1996) J Phys Rev B 54:11169

31. Bloechl PE (1994) Phys Rev B Condens Matter 50:17953

32. Hammer B, Hansen LB, Norskov JK (1999) Phys Rev B Condens Matter Mater Phys 59:7413

33. Monkhorst HJ, Pack JD (1976) Phys Rev B Condens Matter Mater Phys 13:5188

34. Somorjai GA (1994) Introduction to surface chemistry and catalysis. Wiley-Interscience, New York

35. Maitlis PM, Zanotti V (2009) Chem Commun 1619

36. Andersson MP, Abild-Pedersen F, Remediakis IN, Bligaard T, Jones G, Engbaek J, Lytken O, Horch S, Nielsen JH, Sehested J, Rostrup-Nielsen JR, Norskov JK, Chorkendorff I (2008) J Catal 255:6 